\title{
RISCO DE INUNDAC̣ÃO NA CIDADE DE BELÉM (PA): A PERCEPC̣ÃO TÉCNICA E SOCIAL DO RISCO
}

\section{FLOODING RISK IN BELÉM (PA) CITY: THE TECHNICAL AND SOCIAL PERCEPTION OF RISK}

\author{
João Vyctor do Vale Von Paumgartten ${ }^{1}$ \\ Luiz Maurício Furtado Maués ${ }^{2}$ \\ Cecília Alexandra Abreu Coelho Rocha ${ }^{3}$
}

\begin{abstract}
Resumo
Crescentemente, uma diversidade de fenômenos naturais como inundações estão se manifestando nas cidades provocando vários desastres, além de metade da população mundial estar vivendo em centros urbanos cada vez mais vulneráveis. A cidade de Belém (PA) é um exemplo de cidade que apresenta histórico de inundações em decorrência de eventos climáticos frequentes como fenômenos de maré alta e aumento da precipitação pluviométrica, além de $54 \%$ da sua população residir em aglomerados subnormais (favelas). Assim, o objetivo desta pesquisa é identificar o risco de inundação em Belém. $\mathrm{O}$ método utilizado tem como premissa a combinação de parâmetros técnicos e julgamentos sociais na identificação do risco. Pelo lado técnico, utiliza-se um modelo matemático para constituir os índices de risco, exposição e vulnerabilidade a partir de indicadores sociais, econômicos e ambientais, resultando em mapas cartográficos através de um Sistema de Informação Geográfica (SIG). Pelo lado social, aplica-se um questionário com o intuito de identificar o pensamento comum a partir da convivência da população com os episódios de inundação, resultando em dados percentuais de frequência das inundações e os prejuízos experimentados. As análises resultaram na identificação de quatro áreas distintas de risco divididas pelos distritos de: Belém; Sacramenta e Guamá; Entroncamento, Benguí e Icoaraci; Outeiro e Mosqueiro. Os resultados mostram uma heterogeneidade espacial com forte influência do processo histórico de urbanização do município de Belém.
\end{abstract}

Palavras-chave: Inundação. Risco. Exposição. Vulnerabilidade. Desastre.

\footnotetext{
Abstract

${ }^{1}$ Mestre em Planejamento e Gestão do Território pela Universidade Federal do ABC, Santo André - SP, Brasil. E-mail: joaovonp@gmail.com

${ }^{2}$ Doutor em Engenharia Civil (UFPA). Professor da Universidade Federal do Pará, Belém - PA, Brasil. E-mail: maues@ufpa.br

${ }^{3}$ Doutora em Engenharia Civil. Professora da Universidade do Porto, Porto, Portugal. E-mail: carocha@fe.up.pt
} 
Increasingly, a diversity of natural events such as floods has been more present in cities, causing numerous disasters, and besides that, the world's population is living in increasingly vulnerable urban centers. Belém (PA) is an example of a city that has flooding records due to the frequent climatic events (high tides and increased rainfall), added to the fact that $54 \%$ of its population live in subnormal agglomerations (slums). Thus, this research aims to identify the flood risk in Belém. The method has a premise on the combination of technical parameters and social judgments in identifying the risk. On the technical aspect, a mathematical model is used to constitute the risk, exposure, and vulnerability indexes based on social, economic, and environmental indicators, having as results cartographic maps developed using Geographic Information System (GIS). On the social view, a questionnaire is applied to identify common thinking based on the population's experience living with floods, resulting in percentage data on the frequency of floods and the losses experienced. The analyses identified four distinct risk areas divided by the districts of Belém; Sacramenta and Guamá; Entroncamento, Benguí and Icoaraci; Outeiro and Mosqueiro. The results show a spatial heterogeneity with a strong influence on the historical urbanization process of the city of Belém.

Keywords: Flooding. Risk. Exposure. Vulnerability. Disaster.

\section{Introdução}

A rápida urbanização trouxe prosperidade e oportunidade às pessoas, cidades se tornaram em motores econômicos e centros de tecnologia e inovação de seus países, mas este é o caso de cidades bem planejadas e administradas. Por outro lado, as cidades têm se transformado em grandes centros geradores de riscos quando o crescimento se liga aos impactos de eventos climáticos extremos e ao aumento da pobreza (UNISDR, 2012).

Em 2016, em âmbito global, 569,4 milhões de pessoas foram afetadas por desastres naturais, maior número já medido desde 2006. Além disso, aproximadamente um bilhão de pessoas estão residindo em favelas urbanas (CRED, 2016; UNISDR, 2010). Assim, percebe-se que há duas situações preocupantes: muitas pessoas estão vulneráveis e as ocorrências de desastres naturais estão crescendo.

Em Belém, a inundação é entendida como um processo hidrológico de transbordamento das águas dos canais de drenagem para áreas marginais e submersão das áreas costeiras devido à elevação temporária do nível de água. As causas são eventos climáticos frequentes no período de inverno amazônico, geralmente com início em dezembro e término em maio, como o aumento da precipitação pluviométrica e os fenômenos de maré alta, sendo potencializadas pelas condições topográficas, impermeabilização do solo e ineficiência da infraestrutura de drenagem (CAMPOS et al, 2014; CPRM, 2015; PINHEIRO, 2015; PONTES et al, 2017).

De acordo com o último censo demográfico (IBGE, 2010), Belém possui aproximadamente 1,4 milhão de habitantes, sendo que 758.524 mil pessoas residem em aglomerados subnormais (ver IPEA, 2014, p. 11), ou seja, 54\% da população vivem em condições de vulnerabilidade. Ests dado se torna ainda mais grave em comparação com outras capitais importantes, pois Belém está na frente nesse quesito, por exemplo, São Paulo 11\%, Rio de Janeiro 22\% e Salvador 33\%.

Sendo assim, o objetivo desta pesquisa é identificar o risco de inundação na cidade de Belém, de modo que seja obtida uma maior compreensão ao integrar dois prismas de análise: o técnico e o social. Este trabalho ganha maior relevância por essa combinação, pois não se encontra restrito somente a uma percepção do risco, contribuindo também para posteriores pesquisas e discussões.

\section{Riscos e vulnerabilidades}

Os estudos sobre os riscos são particularizados e fragmentados para cada área de conhecimento conforme suas perspectivas de entendimento (MARANDOLA JR.; HOGAN, 2005 apud SANTOS et al, 2015), isto é, são produzidos nas perspectivas da geografia, geologia, sociologia, entre outras áreas, reunindo um conjunto significados.

Para a geógrafa francesa Veyret, as causas e consequências dos riscos devem ser conhecidas, conforme a diversidade das classificações (VEYRET, 2007 apud SOUZA; LOURENÇO, 2015). Inicialmente, considerava-se na abordagem dos riscos naturais os danos e a exposição populacional, 
posteriormente, incorporaram-se os riscos sociais e tecnológicos, passando a se chamar riscos ambientais. Assim, os riscos são entendidos pela manifestação da natureza em conjunto com a maneira na qual a sociedade tem se apoderado do mundo onde vive (EGLER, 1996 apud SOUZA; LOURENÇO, 2015)

$\mathrm{Na}$ Geologia, os estudos consideram que a dinâmica natural do planeta é composta por processos que independem das atividades humanas, entretanto a ação do homem em decorrência das mudanças do uso e ocupação do solo pode estimular, agilizar e aumentar muitos desses processos (CERRI; AMARAL, 1998; BARBOSA; FURRIER, 2017).

Com o objetivo de tornar a compreensão mais fácil, foram estabelecidas categorias de análise dos riscos, sendo acompanhados por um adjetivo que os qualifica e com a determinação clara das ameaças que os constituem (VEYRET, 2007; CASTRO et al, 2005 apud ALMEIDA, 2012; CERRI; AMARAL, 1998 apud ROCHA, 2005 apud SANTOS et al, 2015):

- Riscos naturais: Furacões, secas, tempestades, granizo, raios, enchentes, inundações, terremotos, atividades vulcânicas, tsunamis, deslizamentos, erosão, doenças provocadas por vírus, bactérias, picadas de animais venenosos, etc.

- Riscos tecnológicos: Vazamentos de produtos tóxicos, inflamáveis, radioativos, incêndios acidentais, colisão de veículos, queda de aviões, etc.

- Riscos econômicos, geopolíticos e sociais: Crises econômicas, insegurança e violência em virtude da segregação socioespacial urbana, conflitos políticoideológicos, etc.

Os riscos ambientais são considerados como a maior categoria de análise, abrangendo os riscos naturais, tecnológicos, econômicos, geopolíticos e sociais. Ressalta-se que essa classificação é realizada para facilitar o raciocínio dos tipos de riscos existentes, haja vista que um fenômeno pode estar presente em mais de um dos grupos. Por exemplo, a inundação urbana pode ter causa puramente natural, mas também pode ser influenciada pelas atividades humanas de impermeabilização do solo, drenagem urbana insuficiente e moradias em áreas de inundação.

Ao ampliar o conceito de risco à luz da Sociologia, uma questão importante é a percepção social do risco, entendido como um produto social que somente existe porque uma sociedade ou indivíduo é capaz de percebê-lo (percepção construtivista). Porém, há quem defenda a existência do risco independente de ser percebido, não interferindo no impacto que pode acontecer (percepção objetivista ou realista). Dessa maneira, entende-se que a percepção social é inegável, embora não possa ficar restrita em si mesma, sendo que a análise dos riscos no espaço urbano deve compreender a combinação de juízos sociais e parâmetros científicos (GUIVANT, 1998; VEYRET, 2007; TAVARES et al, 2017).

Outro conceito intrínseco ao risco é a vulnerabilidade que pode ser definido pelas características de uma sociedade que potencializam a suscetibilidade de consequências negativas quando uma ameaça é manifestada (UNISDR, 2009 apud KELMAN, 2018).

Para a autora Cutter, as diferentes abordagens da vulnerabilidade existentes resultam em três posturas principais (CUTTER, 1996 apud MARANDOLA JR; HOGAN, 2005 apud SOUZA; LOURENÇO, 2015). A primeira vulnerabilidade tem como premissa a dimensão espacial ou geográfica, sendo entendida como resultado dos aspectos físicos de uma determinada região, designada pela medida na qual um ambiente é suscetível a ocorrência de ameaças naturais, ou seja, diz respeito as áreas onde ocorre a manifestação de um fenômeno natural (TAGLIANI, 2003; ALVES, 2006 apud ESTEVES, 2011; PINHEIRO, 2015).

A segunda vulnerabilidade está relacionada com as características da comunidade, contrapondo o sentido físico dos riscos, levando em consideração questões econômicas, a oferta e acesso a serviços públicos, os modos de vida da população residente em áreas de riscos, entre outros. Nesse sentido, a vulnerabilidade diz respeito não apenas as populações que se encontram expostas, mas também como resultado das carências sociais que as atingem (CUTTER, 2006; 2010 apud MENDES et al, 2011; PINHEIRO, 2015).

A terceira é a combinação das dimensões sociais e ambientais na identificação e análise da vulnerabilidade, assim, torna-se pertinente o uso da terminologia vulnerabilidade socioambiental, isto porque os riscos ambientais dependem de fatores sociais, econômicos, tecnológicos, culturais, ambientais, etc. (ESTEVES, 2011; PINHEIRO, 2015).

Por último, outra questão relevante sobre as ameaças e vulnerabilidades diz respeito a possibilidade de todos esses elementos serem visualizados através de um Sistema de Informação Geográfica (SIG) para a construção de indicadores físicos e sociais. O SIG pode integrar fontes 
diversificadas de dados e auxiliar o entendimento sobre os riscos e vulnerabilidades, além de poder auxiliar na tomada de decisão para se intervir no território (CUTTER, 2003 apud SOUZA; LOURENÇO, 2015).

De acordo com Marcelino (2008), entende-se que um indicador contempla uma diversidade de dados (mapas, medições em campo, imagens de satélites, questionários, etc.) que possibilitam a identificação das características e o contexto do ambiente. Para o autor "sempre que possível, devese utilizar dados quantitativos, de fontes confiáveis, longas séries históricas e métodos de análise que envolvam modelos matemáticos e físicos". O objetivo é que a avaliação do risco seja o mais próximo da realidade do local e não a percepção do técnico responsável pela análise, além de que esta avaliação seja possível de replicação e comparação com outras áreas.

Para KOBIYAMA (2004 apud MARCELINO et al, 2006), o mapeamento das áreas de risco é o objetivo de um instrumento de análise, pois a partir de um mapa é possível elaborar uma série de ações preventivas, emergenciais e conjuntas entre população e poder público, com o intuito de proporcionar uma defesa permanente da sociedade contra um desastre natural.

\section{Método}

Este trabalho é uma pesquisa exploratória constituída pelo método de modelagem matemática, levantamento e estudo de caso conforme referencial teórico, composta por duas etapas de análise. A primeira etapa diz respeito ao ponto de vista técnico com a utilização de um modelo matemático que permite visualizar e analisar os diferentes níveis de exposição, vulnerabilidade e risco de inundação através da coleta de indicadores sociais, econômicos e ambientais, resultando na criação de mapas cartográficos com utilização de um SIG.

A segunda etapa diz respeito ao ponto de vista social com a aplicação de um questionário a uma parcela da população com o objetivo de construir o entendimento de como a população percebe os episódios de inundação, resultando em dados percentuais de frequência das inundações e os prejuízos experimentados.

Inicialmente, busca-se construir um índice do risco de inundação numa escala intramunicipal, sendo adaptado o índice Disaster Risk Indicators in Brazil (DRIB - Indicadores de Risco de Desastre no Brasil) que é desenvolvido numa escala municipal. O índice DRIB, por sua vez, está baseado no World Risk Index (Índice Mundial de Risco) cujos conceitos teóricos, no âmbito dos desastres naturais, afirmam que o risco deriva de uma combinação entre fatores físicos e a vulnerabilidade de elementos expostos, tendo como premissa de cálculo a equação 1 (ALMEIDA $e t$ al, 2016; WRR, 2016):
$R=E \times V$
Eq. 1

Onde o índice de riscos $(\boldsymbol{R})$ é o produto entre o índice de exposição $(\boldsymbol{E})$ e $o$ índice de vulnerabilidade $(\boldsymbol{V})$, sendo os valores numéricos desses componentes compreendidos entre zero e um, isto é, 0 (zero) indica que não há exposição, vulnerabilidade ou risco e 1 (um) indica que estes são máximos. Para a visualização dos índices são elaborados mapas cartográficos através do programa computacional Quantum Geographic Information System (QGIS) sendo os dados numéricos classificados qualitativamente em cinco classes: muito baixo $(0,00-0,20)$; baixo $(0,21-$ $0,40)$; médio $(0,41-0,60)$; alto $(0,61-0,80)$; e muito alto $(0,81-1,00)$.

Diante do exposto, o primeiro passo é conhecer a exposição através dos seguintes arquivos georreferenciados: áreas suscetíveis à inundação (CPRM, 2015; GEOFABRIK, 2018); mapa territorial e dados populacionais (IBGE, 2010). No QGIS, os dados populacionais são vinculados ao mapa territorial para identificação das diferentes densidades demográficas, assim, pode-se sobrepor o mapa das áreas suscetíveis à inundação ao mapa territorial e aplicar a interseção entre essas duas camadas.

Por último, os diferentes níveis de exposição são identificados na escala distrital - elemento unitário do Sistema Municipal de Planejamento e Gestão Urbana (BELÉM, 2012) - assim, a população exposta de um distrito é dividida pela população total, resultando em uma cartografia que representa a dinâmica espacial do risco, ver equação 1.1 demonstrada a seguir (adaptado de ALMEIDA et al, 2016):

$$
E=\frac{\text { População exposta }}{\text { População total }} \quad \text { Eq. } 1.1
$$

O segundo passo é conhecer a vulnerabilidade através de trinta e dois indicadores que compreendem as condições sociais, econômicas e ambientas do território brasileiro, sendo divididos em suscetibilidade $(\boldsymbol{S})$, capacidade de enfrentamento $(\boldsymbol{C} \boldsymbol{E})$ e capacidade de adaptação $(\boldsymbol{C} \boldsymbol{A})$. As 
condições socioeconômicas, culturais e o desempenho das instituições públicas em lidar com riscos estão fortemente associadas à vulnerabilidade, levando-se em conta que as séries de desigualdades e a ineficiência do Estado resultam em barreiras para a redução dos riscos. A seguir, apresentam-se os indicadores de vulnerabilidade divididos em categorias:

Quadro 1: Indicadores de vulnerabilidade

\begin{tabular}{|c|c|c|}
\hline Suscetibilidade & & Capacidade de adaptação \\
\hline & & \\
\hline \multirow{5}{*}{$\begin{array}{l}\text { (a) \% de pessoas em } \\
\text { domicílios sem } \\
\text { abastecimento de água } \\
\text { da rede geral } \\
\text { (b) \% de pessoas em } \\
\text { domicílios com banheiro } \\
\text { de uso exclusivo dos } \\
\text { moradores com sanitário } \\
\text { sem esgotamento } \\
\text { sanitário via rede geral de } \\
\text { esgoto ou pluvial }\end{array}$} & & \multirow{3}{*}{$\begin{array}{l}\text { (a) \% de alfabetizados com } 5 \text { ou mais } \\
\text { anos de idade } \\
\text { (b) } \% 15-17 \text { anos com fundamental } \\
\text { completo } \\
\text { (c) } \% 18-24 \text { anos com ensino médio } \\
\text { completo } \\
\text { (d) } \% 25 \text { ou mais anos com ensino } \\
\text { superior completo }\end{array}$} \\
\hline & & \\
\hline & \multirow{8}{*}{$\begin{array}{l}\text { (b) Medidas estruturais } \\
\text { para reduzir o risco de } \\
\text { desastres (barragem, } \\
\text { canais, parque, } \\
\text { reservatórios, etc.) } \\
\text { (c) Gerenciamento de risco } \\
\text { de desastres à inundações } \\
\text { (mapeamento e controle } \\
\text { para evitar ocupação em } \\
\text { áreas suscetíveis, sistema } \\
\text { de alerta, cadastro de risco, } \\
\text { etc.) } \\
\text { (d) População vulnerável à } \\
\text { inundação registrada em } \\
\text { programas habitacionais } \\
\text { (e) Estrutura local para } \\
\text { resposta à desastres } \\
\text { (bombeiros, defesa civil, } \\
\text { núcleos comunitários, etc.) }\end{array}$} & \\
\hline & & \multirow{4}{*}{$\begin{array}{l}\text { Equidade de gênero } \\
\text { (e) Instituição responsável pela } \\
\text { formulação, coordenação e } \\
\text { implementação de políticas para } \\
\text { mulheres com orçamento específico } \\
\text { (f) Município tem plano de políticas para } \\
\text { mulheres } \\
\text { (g) \% de mulheres responsáveis por } \\
\text { famílias com } 10 \text { ou mais anos }\end{array}$} \\
\hline & & \\
\hline & & \\
\hline \multirow{3}{*}{$\begin{array}{l}\text { (c) \% da população em } \\
\text { aglomerados subnormais } \\
\text { (favelas) } \\
\text { (d) \% de pessoas em } \\
\text { domicílios com materiais } \\
\text { inadequados nas paredes } \\
\text { (e) Grau de urbanização }\end{array}$} & & \\
\hline & & \multirow{3}{*}{$\begin{array}{l}\text { Condições ambientais / Proteção do } \\
\text { ecossistema } \\
\text { (h) Políticas e ações específicas para o } \\
\text { meio ambiente } \\
\text { (i) Áreas de desmatamento } \\
\text { (j) Áreas de conservação } \\
\text { (k) Pontos de fogo }\end{array}$} \\
\hline & & \\
\hline \multirow{3}{*}{$\begin{array}{l}\text { Pobreza e dependência } \\
\text { (f) Razão de dependência } \\
\text { (g) \% Vulneráveis à } \\
\text { pobreza (\% de pessoas } \\
\text { responsáveis por família } \\
\text { sem rendimento mensal) } \\
\text { Capacidade econômica e } \\
\text { renda }\end{array}$} & & \\
\hline & & \\
\hline & & \multirow{5}{*}{$\begin{array}{l}\text { (I) Legislação e instrumentos de } \\
\text { planejamento (plano diretor, } \\
\text { zoneamento, código de obras, etc.) } \\
\text { (m) Ferramentas de planejamento } \\
\text { específicas para prevenção de } \\
\text { desastres (legislação para prevenção de } \\
\text { riscos, plano municipal de redução de } \\
\text { riscos, carta geotécnica de aptidão à } \\
\text { urbanização, etc.) } \\
\text { (n) Administração Pública aderiu a } \\
\text { agenda de compromissos para os } \\
\text { objetivos de desenvolvimento do milênio } \\
\text { Investimentos }\end{array}$} \\
\hline \multirow{5}{*}{$\begin{array}{l}\text { (h) \% domicílios com } \\
\text { rendimento de até } 1 \\
\text { salário mínimo mensal } \\
\text { (i) Índice de Gini (grau de } \\
\text { desigualdade na } \\
\text { distribuição de indivíduos } \\
\text { segundo a renda } \\
\text { domiciliar per capita / a } \\
\text { renda domiciliar per } \\
\text { capita tem o mesmo } \\
\text { valor) }\end{array}$} & & \\
\hline & & \\
\hline & & \\
\hline & & \\
\hline & & \\
\hline
\end{tabular}

A seleção dos indicadores se baseia no World Risk Index, sendo relacionados aos oito Objetivos de Desenvolvimento do Milênio e ao Quadro de Ação de Hyogo para Redução do Risco de Catástrofes da Organização das Nações Unidas (ALMEIDA et al, 2016). Ressalta-se que os indicadores aqui tratados se referem a dados técnicos coletados em diversas fontes oficiais e publicamente disponíveis, ou seja, a exposição, a vulnerabilidade e o risco propriamente dito são identificados a partir de dados numéricos e georreferenciados.

No Quadro 2 são apresentados as categorias, os pesos (ponderação), os bancos de dados, os anos de publicação, as escalas e as unidades dos indicadores que compõem a $\boldsymbol{S}, \boldsymbol{C} \boldsymbol{E}$ e $\boldsymbol{C A}$. 
Quadro 2: Informações sobre os indicadores de vulnerabilidade

\begin{tabular}{|c|c|c|c|c|c|c|}
\hline Categorias & Pesos & $\begin{array}{l}\text { Indicadores } \\
\text { (Quadro 2) }\end{array}$ & Banco de dados & Ano de publicação & Escala & Unidade \\
\hline \multicolumn{7}{|l|}{ Suscetibilidade } \\
\hline \multirow{2}{*}{$\begin{array}{l}\text { Infraestrutura } \\
\text { pública }\end{array}$} & \multirow{2}{*}{$(0,22)$} & (a) & \multirow{3}{*}{ Censo Demográfico (IBGE) } & \multirow{3}{*}{2010} & \multirow{3}{*}{ Distrito } & \multirow{3}{*}{$\%$} \\
\hline & & (b) & & & & \\
\hline \multirow{3}{*}{$\begin{array}{l}\text { Condições de } \\
\text { habitação }\end{array}$} & \multirow{3}{*}{$(0,33)$} & (c) & & & & \\
\hline & & (d) & \multirow{3}{*}{$\begin{array}{l}\text { Atlas do Desenvolvimento } \\
\text { Humano no Brasil (UNDP, } \\
\text { IPEA e Fundação João } \\
\text { Pinheiro) }\end{array}$} & \multirow{3}{*}{2010} & \multirow{3}{*}{ Município } & \multirow{3}{*}{$\%$} \\
\hline & & (e) & & & & \\
\hline \multirow{2}{*}{$\begin{array}{l}\text { Pobreza e } \\
\text { dependência }\end{array}$} & \multirow{2}{*}{$(0,22)$} & (f) & & & & \\
\hline & & $(\mathrm{g})$ & \multirow{2}{*}{ Censo Demográfico (IBGE) } & \multirow{2}{*}{2010} & \multirow{2}{*}{ Distrito } & \multirow{2}{*}{$\%$} \\
\hline \multirow[b]{2}{*}{$\begin{array}{l}\text { Capacidade } \\
\text { económica e } \\
\text { renda }\end{array}$} & \multirow[b]{2}{*}{$(0,22)$} & (h) & & & & \\
\hline & & (i) & $\begin{array}{l}\text { Atlas do Desenvolvimento } \\
\text { Humano no Brasil (UNDP, } \\
\text { IPEA e Fundação João } \\
\text { Pinheiro) }\end{array}$ & 2010 & Município & Índice \\
\hline \multicolumn{7}{|c|}{ Capacidade de enfrentamento } \\
\hline $\begin{array}{l}\text { Governança } \\
\text { e autoridades }\end{array}$ & $(0,11)$ & (a) & $\begin{array}{l}\text { Boll, } 2010 \text { (Dissertação de } \\
\text { mestrado) }\end{array}$ & 2010 & Estado & Índice \\
\hline \multirow{3}{*}{$\begin{array}{l}\text { Preparação à } \\
\text { desastres e } \\
\text { alerta } \\
\text { antecipado }\end{array}$} & \multirow{3}{*}{$(0,55)$} & (b) & \multirow{3}{*}{$\begin{array}{l}\text { Perfil dos Municípios } \\
\text { Brasileiros - MUNIC (IBGE) }\end{array}$} & \multirow{3}{*}{2013} & \multirow{3}{*}{ Município } & \multirow{3}{*}{ Razão } \\
\hline & & (c) & & & & \\
\hline & & (d) & & & & \\
\hline & & & Demografia Médica no Brasil & & & \\
\hline Serviços & (ด 2?) & (f) & (FMUSP) & 2015 & Município & Razão \\
\hline médicos & $(0, \angle<)$ & (g) & $\begin{array}{l}\text { Pesquisa de Assistência } \\
\text { Médico-Sanitária (IBGE) }\end{array}$ & 2009 & Município & Razão \\
\hline $\begin{array}{l}\text { Cobertura } \\
\text { material }\end{array}$ & $(0,11)$ & (h) & $\begin{array}{l}\text { Relatório de Informações } \\
\text { Sociais - Bolsa Família e } \\
\text { Cadastro Único (Ministério do } \\
\text { Desenvolvimento Social e } \\
\text { Agrário) }\end{array}$ & 2018 & Município & Razão \\
\hline Capacidade $d \epsilon$ & adaptas & & & & & \\
\hline & & (a) & Censo Demográfico (IBGE) & 2010 & Distrito & Razão \\
\hline Educação e & & (b) & Atlas do Desenvolvimento & & & \\
\hline pesquisa & $(0,26)$ & (c) & Humano no Brasil (UNDP, & 2010 & Município & $\%$ \\
\hline & & (d) & Pinheiro) & & & \\
\hline Equidade de & & (e) & Perfil dos Municípios & 2013 & Município & Razão \\
\hline género & $(0,20)$ & $(\mathrm{f})$ & Brasileiros - MUNIC (IBGE) & & & \\
\hline & & (g) & $\begin{array}{l}\text { Censo Demográfico (IBGE) } \\
\text { Perfil dos Municípios }\end{array}$ & 2010 & Distrito & Razao \\
\hline & & (h) & Brasileiros - MUNIC (IBGE) & 2013 & Município & Razão \\
\hline $\begin{array}{l}\text { Condições } \\
\text { ambientais / } \\
\text { Proteção do } \\
\text { ecossistema }\end{array}$ & $(0,26)$ & (i) & $\begin{array}{l}\text { Monitoramento do } \\
\text { Desmatamento das } \\
\text { Formações Florestais na } \\
\text { Amazônia Legal - PRODES } \\
\text { (INPE) }\end{array}$ & 2017 & Município & Razão \\
\hline & & (j) & $\begin{array}{l}\text { Unidade de Conservação } \\
\text { (Ministério do Meio Ambiente) }\end{array}$ & 2018 & Estado & Razão \\
\hline & & $(k)$ & Programa Queimadas (INPE) & 2016 & Estado & Razão \\
\hline Estratégias & $(020)$ & (I) & Perfil dos Municípios & 2013 & Municínin & Bazão \\
\hline de adaptação & $(0,<U)$ & (n) & Brasileiros - MUNIC (IBGE) & & & \\
\hline Investimentos & $(0,06)$ & (o) & $\begin{array}{l}\text { Atlas do Desenvolvimento } \\
\text { Humano no Brasil (UNDP, } \\
\text { IPEA e Fundação João } \\
\text { Pinheiro) }\end{array}$ & 2010 & Município & $\%$ \\
\hline
\end{tabular}


Em relação ao Quadro 2, a suscetibilidade diz respeito a pré-disposição da população em sofrer danos, compreendendo nove indicadores (a, b, c, d, e, f, g, h, i) divididos em quatro categorias (infraestrutura urbana; condições de habitação; pobreza e dependência; capacidade econômica e renda).

A capacidade de enfrentamento diz respeito à capacidade do município em se preparar antes, resistir durante e recuperar após os impactos da inundação. São utilizados oito indicadores (a, b, c, $\mathrm{d}, \mathrm{e}, \mathrm{f}, \mathrm{g}, \mathrm{h}$ ) divididos em quatro categorias (governança e autoridades; preparação a desastres e alerta antecipado; serviços médicos; cobertura material).

A capacidade de adaptação diz respeito à capacidade do município e da população em se transformar enquanto sociedade, por exemplo, a equidade de gênero e a preservação do meio ambiente são considerados temas contemporâneos que podem indicar em qual medida uma sociedade é capaz de se adaptar. São utilizados quinze indicadores (a, b, c, d, e, f, g, h, i, j, k, l, m, n, o) divididos em cinco categorias (educação e pesquisa; equidade de gênero; condições ambientais / proteção do ecossistema; estratégias de adaptação; investimentos).

$O$ valor de cada indicador da capacidade de enfrentamento $(\boldsymbol{C} E)$ e da capacidade de adaptação (CA) é subtraído de 1 (um) para compor a falta desses indicadores (FCE e $\boldsymbol{F C} \boldsymbol{A}$ ), uma vez que a soma global dos componentes da vulnerabilidade será uma medida de deficiências das capacidades para lidar com o risco de inundação. A seguir, demonstra-se a sequência de cálculo da vulnerabilidade (adaptado de ALMEIDA et al, 2016):

$$
\begin{aligned}
& \boldsymbol{V}=0,33 \times(S+F C E+F C A) \\
& \boldsymbol{S}=(0,20 \times(0,50 \times(a+b)))+(0,30 \times(0,33 \times(c+d+e)))+(0,25 \times(0,50 \times(f+ \\
& g)))+(0,25 \times(0,50 \times(h+i))) \\
& \boldsymbol{F C} \boldsymbol{E}=(0,11 \times a)+(0,55 \times(0,25 \times(b+c+d+e)))+(0,22 \times(0,50 \times(f+g)))+ \\
& (0,11 \times h) \\
& \boldsymbol{F C A}=(0,26 \times(0,25 \times(a+b+c+d)))+(0,20 \times(0,33 \times(e+f+g)))+(0,26 \times \\
& (0,25 \times(h+i+j+k)))+(0,20 \times(0,33 \times(l+m+n)))+(0,06 \times o)
\end{aligned}
$$

Eq. 1.2

Eq. 1.2.1

Eq. 1.2 .2

Eq. 1.2.3

Sobre os ajustes de cálculo, a maioria dos indicadores estão em porcentagem, sendo divididos por 100 (cem) para se chegar num intervalo de 0 (zero) a 1 (um). Além disso, tem-se a unidade razão que é a divisão do valor do indicador pelo seu total, assim, com base nas informações recenseadas, sabe-se quantas medidas já foram e devem ser implementadas.

Por fim, para efeitos de análise comparativa, buscam-se indicadores na menor escala possível, sendo identificadas três escalas: distrito; município; e estado, apesar disso, essa limitação não impede a realização da análise, apenas reduz uma maior distinção entre as áreas.

A percepção social do risco de inundação se desenvolve através da aplicação de um questionário para se levantar como a população convive com os episódios de inundação. Assim, na elaboração do questionário, primou-se por perguntas simples, de fácil resposta, com objetivo de alcançar interpretações fiéis. Ressalta-se também que se utiliza uma amostra representativa da população, isenta de qualquer tendência ou pré-julgamento. 0 intuito é realmente coletar a percepção da população, sem fornecer qualquer informação prévia ou selecionar qualquer grupo propenso ao risco e vulnerável socialmente. Assim, aplica-se o questionário por diversos meios e locais, com o objetivo de buscar a maior e mais diversificada participação da população.

O questionário foi elaborado para ser aplicado por meio de formulário eletrônico (Google Forms) e por via impressa em papel, sendo o tratamento dos dados feito através do Microsoft Office Excel 2016. O tamanho da amostra ideal (n) foi definido de acordo com AYRES et al (2015), através da equação 2 :

$$
n=\frac{N \times n_{0}}{N+n_{0}} \quad \text { Eq. } 2
$$

Sendo $\boldsymbol{N}$ o tamanho da população e $\boldsymbol{n}_{0}$ o tamanho da amostra provisória que considera a margem de erro (Er) em termos probabilísticos de $5 \%$, assim, primeiramente, deu-se o cálculo de $\boldsymbol{n}_{0}$ com base na margem de erro para se conhecer o tamanho da amostra provisória:

$$
\boldsymbol{n}_{0}=\frac{1}{E r^{2}}=\frac{1}{(0.05)^{2}}=400 \quad \text { Eq. } 2.1
$$

Portanto, para um tamanho da população igual a 1.392.332 habitantes (IBGE, 2010), a quantidade do questionário a ser aplicado se dá através do cálculo a seguir:

$$
\boldsymbol{n}=\frac{1.392 .332 \times 400}{1.392 .332+400}=400 \text { questionários } \quad \text { Eq. } 2
$$


Inicialmente, realizou-se a validação do questionário através de uma aplicação experimental para determinação da qualidade das questões, isto é, daquilo que estavam propostas a medir.

Com os devidos ajustes, a aplicação definitiva ocorreu através de um pedido de colaboração enviado aos e-mails dos alunos, funcionários e professores da Faculdade de Engenharia Civil (FEC) da Universidade Federal do Pará (UFPA) com o link do questionário inserido Google Forms e, em seguida, aplicou-se aleatória e presencialmente o questionário aos alunos da FEC. $O$ fato do questionário (em meio eletrônico) ter sido aplicado às pessoas que frequentam a UFPA, ocorreu pelo simples fato de ter acesso aos seus $e$-mails, mas esses respondentes abrangem uma amostra ampla e representativa da cidade, pois residem em diferentes distritos do município alvo da pesquisa.

Por fim, em busca de diversificar o público, contou-se com a colaboração dos agentes da Defesa Civil que permitiram a entrevista com a população na ação social promovida pela Prefeitura de Belém no bairro da Pedreira no dia 04 de abril de 2018 (BELÉM, 2018).

$\mathrm{Na}$ primeira seção do questionário, através de cinco questões como gênero, idade, escolaridade, ocupação e distrito de residência, pretende-se caracterizar os entrevistados. Na segunda seção, as cinco questões têm como objetivo aferir a sensação de risco, memória, frequência, se já foi afetado e os danos experimentados (Quadro 3).

Quadro 3 - Questionário de percepção social do risco de inundação

\begin{tabular}{|l|}
\hline I-Características sociodemográficas \\
\hline Gênero (Marcar apenas uma resposta): \\
\hline Idade (Marcar apenas uma resposta): \\
\hline Escolaridade (Marcar apenas uma resposta): \\
\hline $\begin{array}{l}\text { Qual sua ocupação (Marcar apenas uma } \\
\text { resposta): }\end{array}$ \\
\hline $\begin{array}{l}\text { Qual seu distrito de residência (Marcar apenas } \\
\text { uma resposta): }\end{array}$ \\
\hline II - Convivência com as inundações \\
\hline $\begin{array}{l}\text { Assinale a opção que melhor traduz a sensação } \\
\text { de risco (Marcar apenas uma resposta): }\end{array}$ \\
\hline
\end{tabular}

Tem memória de inundação no distrito de residência (Marcar apenas uma resposta)

Numa escala de 1 a 5, onde 1 corresponde

"Raramente" e 5 "Diariamente", assinale a opção que melhor traduz a frequência dos episódios de inundação no distrito de residência (Marcar apenas uma resposta):

Já foi diretamente afetado em algum episódio de inundação (Marcar apenas uma resposta):

Se "Sim" (9), quais as perdas ou danos experimentados nos episódios de inundação (Marcar todas que se aplicam):

( ) Masculino ( ) Feminino ( ) Prefiro não dizer

( ) 15-19 ( ) 20-24 ( ) 25-29 ( ) 30-34 ( ) 35-39 ( ) 4044 ( ) 45-49 ( ) 50-54 ( ) 55-59 ( ) 60-64 ( ) 65+

( ) Analfabeto ( ) Sabe ler / escrever (sem escola) ( ) Ensino Fundamental ( ) Ensino Médio ( ) Ensino Superior Incompleto

( ) Ensino Superior Completo ( ) Pós-Graduação (mestrado e / ou doutorado)

( ) Estudante ( ) Estudante / Trabalhador ( ) Trabalhador por conta própria ( ) Trabalhador por conta de outrém

( ) Desempregado ( ) Aposentado

( ) Belém ( ) Benguí ( ) Entroncamento ( ) Guamá ( ) Icoaraci ( ) Mosqueiro ( ) Outeiro ( ) Sacramenta

( ) Doença ( ) Construção instável ( ) Inundação ( )

Corrupção

( ) Terrorismo ( ) Crime cibernético ( ) Assalto ( ) Outro:

( ) Sim ( ) Não ( ) Não sei

Caso tenha assinalado a resposta Não ou Não sei, não responder as próximas perguntas.

( ) 1 -Raramente ( ) 2 - Anualmente ( ) 3 -Mensalmente

( ) 4-Semanalmente ( ) 5 -Diariamente

( ) Sim ( ) Não ( ) Não sei

( ) Morte de familiares ( ) Feridas / enfermidades

( ) Desalojamento ( ) Prejuízo de mobiliário / equipamentos

( ) Prejuízo de automóveis / motocicletas ( ) Outro:

Destaca-se que a questão 5 permitiu a análise comparativa entre cada distrito do município, além da pergunta 7 que teve a intenção de qualificar os entrevistados a responderem às perguntas seguintes do questionário, ressaltando que caso a resposta fosse negativa para esta pergunta, 0 entrevistado deveria suspender a aplicação do questionário.

\section{Resultados e discussões}


Sabe-se que cidades estão cada vez mais ameaçadas por fenômenos naturais, o que têm preocupado gestores públicos para o combate aos riscos. Nesse sentido, esta pesquisa contribui para o desenvolvimento regional tanto no âmbito de planejamento como gestão. Por exemplo, a promoção de um ordenamento do território que diminua a exposição e a vulnerabilidade populacional ou a adoção de medidas de gestão focadas na construção da resiliência urbana.

$O$ fato é que os riscos urbanos precisam ser encarados com seriedade através de uma visão holística, a fim de se buscar um entendimento integral dos fenômenos. É nessa perspectiva que o objeto deste estudo é explorado, pela combinação da percepção técnica e social, contribuindo para futuras pesquisas e discussões sobre o desenvolvimento regional.

Nesse momento serão apresentados os resultados da percepção técnica de acordo com a divisão distrital oficial do município, ou seja, os distritos que compõem a cidade são Belém, Benguí, Guamá, Entroncamento, Icoaraci, Mosqueiro, Outeiro e Sacramenta (BELÉM, 2012).

O índice de exposição encontrado está entre 0,61 a 1,00, configurando-se como uma situação preocupante, pois os números são elevados, Benguí $(0,637)$, Belém $(0,659)$, Entroncamento $(0,665)$ e Icoaraci $(0,721)$ apresentaram índices altos e Outeiro $(0,829)$, Mosqueiro $(0,935)$, Sacramenta $(0,946)$ e Guamá $(0,994)$ apresentaram índices muito altos. A seguir, demonstra-se o mapa de divisão oficial do município, assim como os índices de exposição encontrados para cada um distrito.

Figura 1: (a) Mapa da divisão político-administrativa; (b) mapa do índice de exposição

(a)

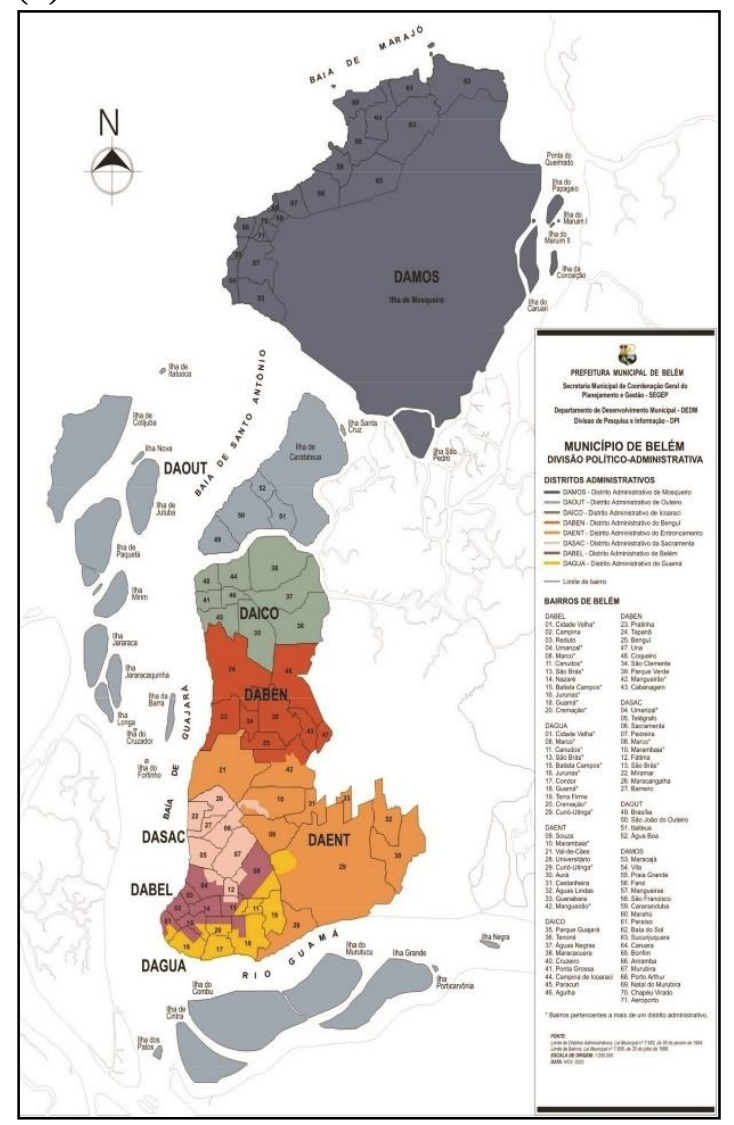

(b)

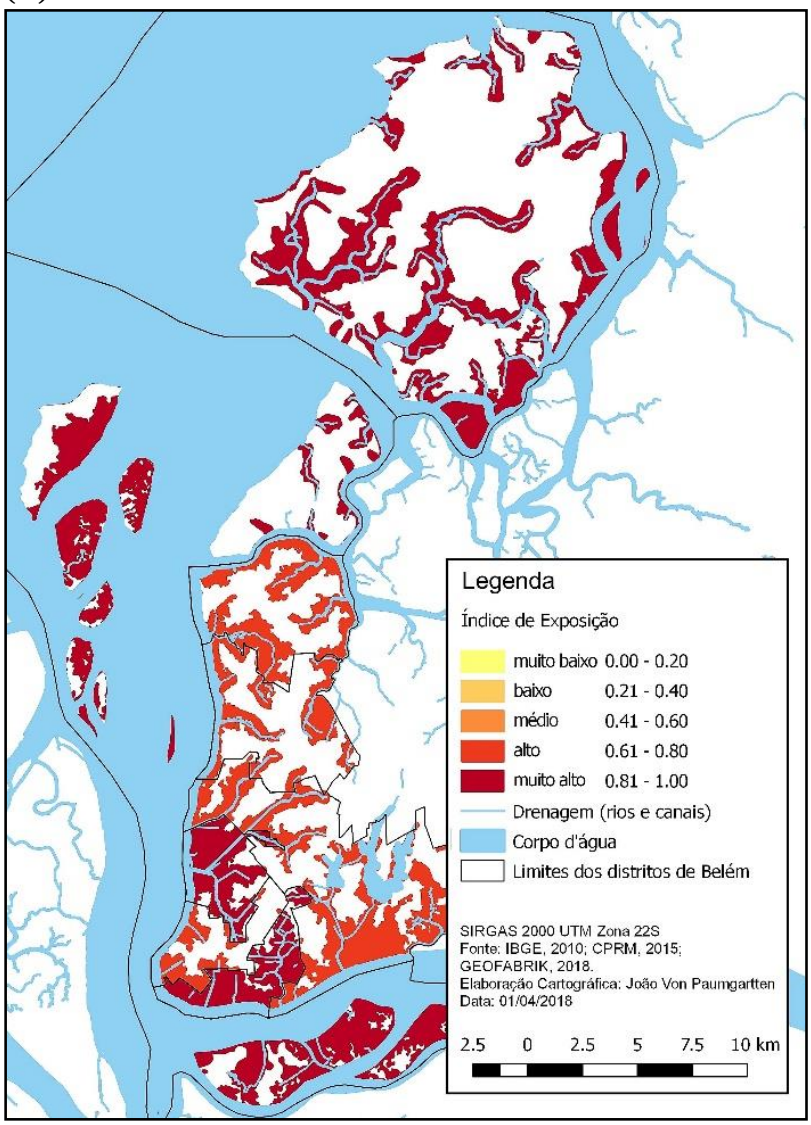

Fonte: (a) BELÉM (2012); (b) elaborado pelor autor

De acordo com a figura acima, percebe-se que a exposição populacional se dá ao longo das adjacências dos canais de drenagem que cortam o território, além de grandes áreas costeiras propensas a inundações. Uma forte característica é a ocupação por moradias irregulares em áreas potencialmente inundáveis e impróprias para uso habitacional.

Em relação aos índices de vulnerabilidade, todos os distritos estão entre 0,41 a 0,60 , isto é, possuem índice de vulnerabilidade médio. Os resultados evidenciam que a população está mais em exposição do que em vulnerabilidade, entretanto vale ressaltar que grande parte dos indicadores vulnerabilidade utilizados estão em escala municipal ou estadual, o que influencia para uma menor distinção entre os distritos. 
Não se pode desprezar que Belém apresenta grandes áreas de aglomerados subnormais e que estas ocupações influenciam para o aumento da vulnerabilidade devido as suas características. Na Figura 2, apresenta-se o mapa do índice de vulnerabilidade juntamente com o mapa dos aglomerados.

Figura 2: (a) Mapa dos aglomerados subnormais; (b) mapa do índice de vulnerabilidade

(a)

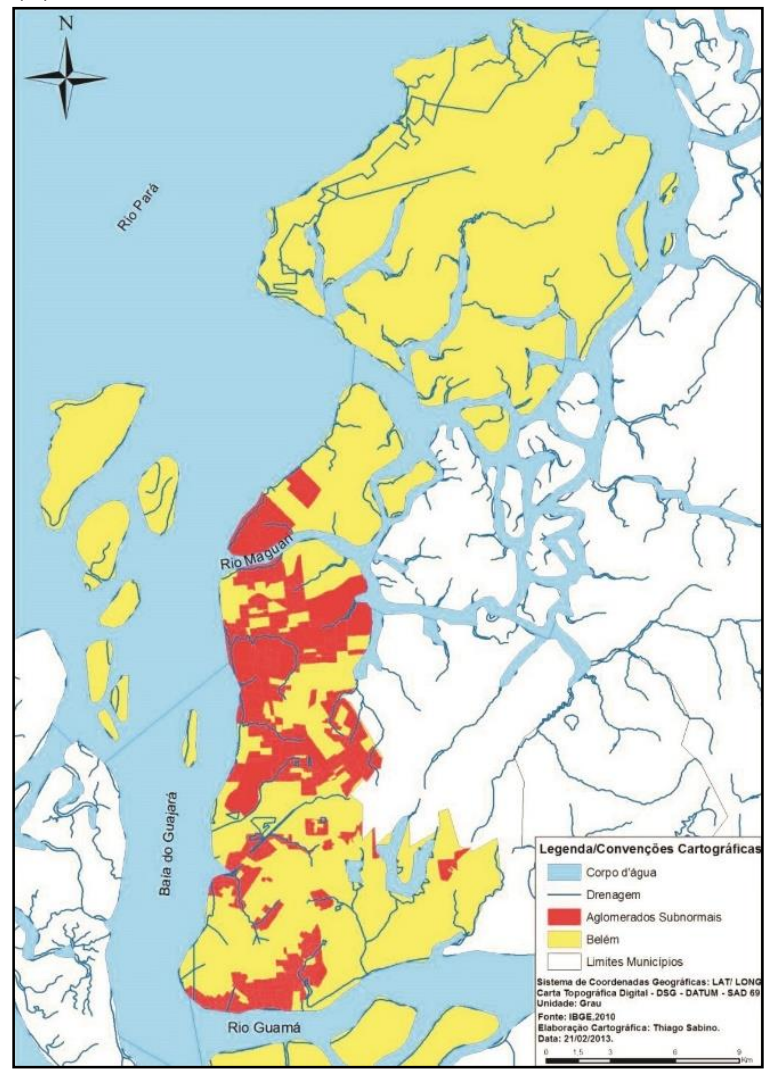

(b)

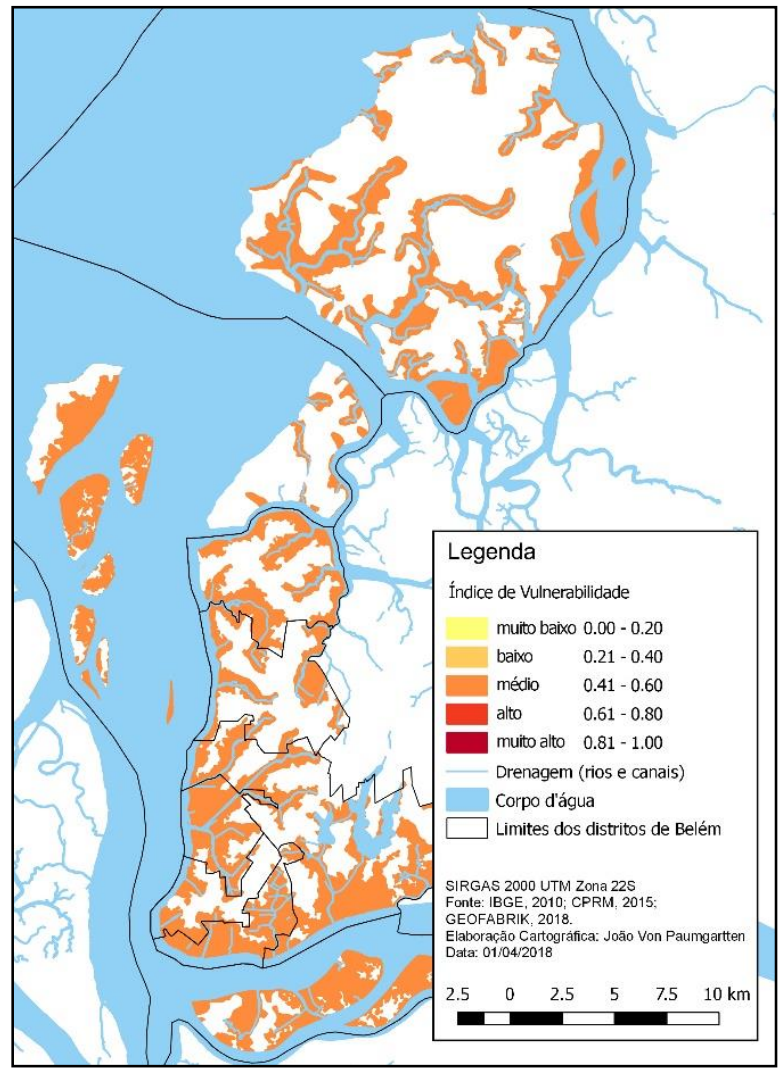

Fonte: (a) PINHEIRO (2015); (b) elaborado pelo autor.

Pode-se ver na figura acima que Belém contém pequenas áreas de aglomerados e apresenta o menor índice de vulnerabilidade $(0,450)$, Entroncamento $(0,475)$, Sacramenta $(0,479)$, Guamá $(0,499)$, Outeiro $(0,505)$, Icoaraci $(0,507)$ e Benguí $(0,517)$ contêm grandes áreas de aglomerados e também são os que apresentam os maiores índices de vulnerabilidade. Em Mosqueiro $(0,486)$, historicamente, sabe-se que há predominância do aspecto rural e suas peculiares deficiências em saneamento básico e infraestrutura urbana.

Portanto, ao finalizar o índice do risco de inundação, Belém $(0,297)$, Entroncamento $(0,316)$, Benguí $(0,329)$ e Icoaraci $(0,366)$ obtiveram classificação de índices baixos, enquanto que Outeiro $(0,418)$, Sacramenta $(0,453)$, Mosqueiro $(0,454)$ e Guamá $(0,496)$, obtiveram índices médios. Em seguida, na Figura 3, apresenta-se o mapa do índice do risco de inundação do município de Belém. 
Figura 3: Índice do risco de inundação

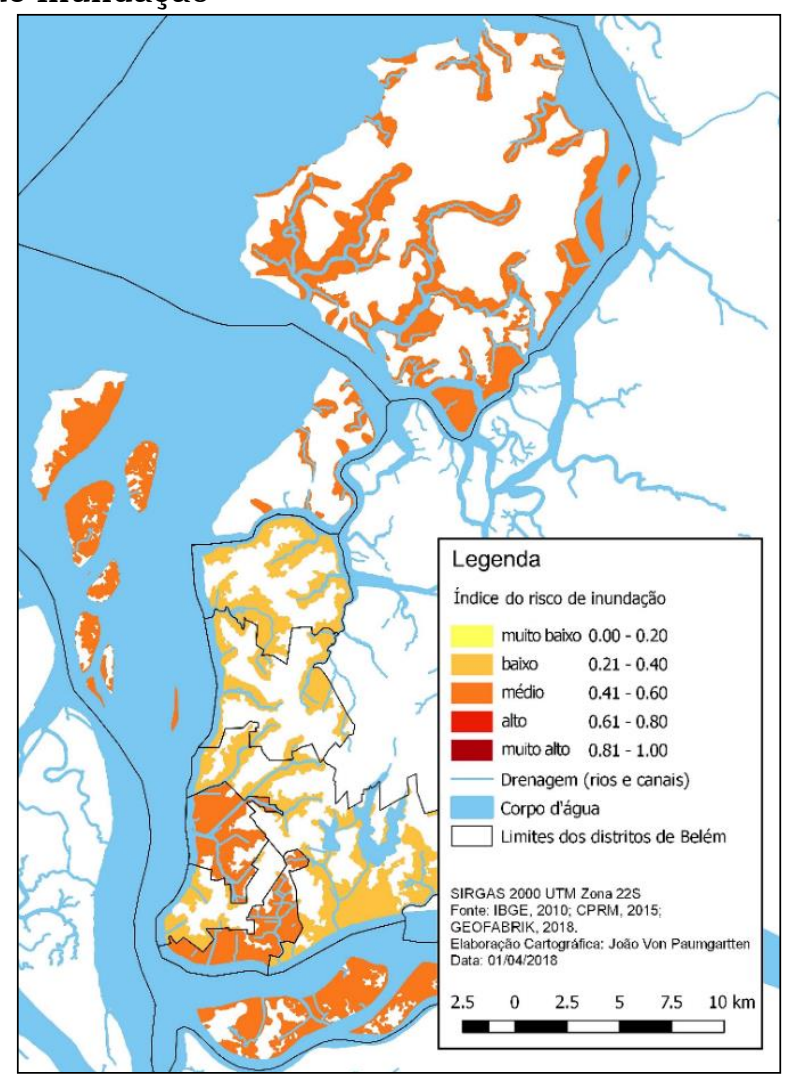

A partir deste tópico, apresenta-se os resultados da percepção social do risco, começando pelo perfil dos entrevistados, ou seja, gênero, idade, escolaridade e ocupação: sexo masculino $(66,01 \%) ; 15$ a 29 anos (62,56\%); ensino superior incompleto (50\%); estudante $(39,41 \%)$ ou estudante/trabalhador (26,60\%). Esse perfil pode ser justificado pela grande participação de alunos e funcionários da Universidade Federal do Pará.

Ao analisar as respostas sobre o distrito de residência, nota-se que grande parcela reside em Belém $(29,06 \%)$ e Sacramenta $(23,40 \%)$, os percentuais do Benguí $(15,27 \%)$, Guamá $(12,56 \%)$ e Entroncamento $(11,58 \%)$ são próximos, já os percentuais de Icoaraci $(3,45 \%)$, Mosqueiro $(2,22 \%)$ e Outeiro $(2,46 \%)$ são relativamente baixos, tendo em conta que esses distritos estão localizados numa distância bem maior em relação ao centro da cidade, tornando mais difícil a aplicação dos questionários nessas áreas. A seguir, apresentam-se os resultados das questões que envolvem a convivência da população com as inundações, classificando por distritos: 
Tabela 1: Convivência com as inundações

\begin{tabular}{|c|c|c|c|c|c|}
\hline $\begin{array}{l}\text { Distrito } \\
\text { administrativo }\end{array}$ & $\begin{array}{l}\text { 6. (...) opção que } \\
\text { melhor traduz a } \\
\text { sensação de risco: }\end{array}$ & $\begin{array}{l}\text { 7. Tem } \\
\text { memória de } \\
\text { inundação } \\
\text { no distrito de } \\
\text { residência: }\end{array}$ & $\begin{array}{l}\text { 8. (....) opção que } \\
\text { melhor traduz a } \\
\text { frequência dos } \\
\text { episódios de } \\
\text { inundação no } \\
\text { distrito de } \\
\text { residência: }\end{array}$ & $\begin{array}{l}\text { 9. Já foi } \\
\text { diretamente } \\
\text { afetado em } \\
\text { algum } \\
\text { episódio de } \\
\text { inundação: }\end{array}$ & $\begin{array}{l}\text { 10. (...) quais as perdas } \\
\text { ou danos } \\
\text { experimentados nos } \\
\text { episódios de inundação }\end{array}$ \\
\hline Belém & $\begin{array}{l}\text { Assalto } 74 \% \\
\text { Inundação 5\% }\end{array}$ & $\operatorname{Sim} 59 \%$ & Anualmente $36 \%$ & $\begin{array}{l}\text { Não 35\%; } \\
\text { Sim 65\% }\end{array}$ & $\begin{array}{l}\text { Prejuízo de automóveis/ } \\
\text { motocicletas } 24 \%\end{array}$ \\
\hline Benguí & $\begin{array}{l}\text { Assalto } 74 \% \\
\text { Inundação } 7 \%\end{array}$ & $\operatorname{Sim} 68 \%$ & Mensalmente $40 \%$ & $\operatorname{Sim} 100 \%$ & $\begin{array}{l}\text { Outro: interdição de via } \\
\text { pública de acesso a } \\
\text { minha residência } 58 \%\end{array}$ \\
\hline Entroncamento & $\begin{array}{l}\text { Assalto } 76 \% \\
\text { Inundação 6\% }\end{array}$ & $\operatorname{Sim} 60 \%$ & Mensalmente $32 \%$ & $\operatorname{Sim} 100 \%$ & $\begin{array}{l}\text { Outro: transtorno no } \\
\text { trânsito } 52 \%\end{array}$ \\
\hline Guamá & $\begin{array}{l}\text { Assalto } 77 \% \\
\text { Inundação } 6 \%\end{array}$ & $\operatorname{Sim} 82 \%$ & $\begin{array}{l}\text { Semanalmente } \\
43 \%\end{array}$ & $\operatorname{Sim} 100 \%$ & $\begin{array}{l}\text { Prejuízo de mobiliários/ } \\
\text { equipamentos } 44 \%\end{array}$ \\
\hline Icoaraci & $\begin{array}{l}\text { Assalto } 79 \% \\
\text { Inundação } 0 \%\end{array}$ & $\operatorname{Sim} 50 \%$ & Mensalmente $57 \%$ & Sim $100 \%$ & $\begin{array}{l}\text { Outro: interdição de via } \\
\text { pública de acesso a } \\
\text { minha residência } 37 \%\end{array}$ \\
\hline Mosqueiro & $\begin{array}{l}\text { Assalto } 78 \% \\
\text { Inundação 0\% }\end{array}$ & Não 67\% & Mensalmente $67 \%$ & $\operatorname{Sim} 100 \%$ & $\begin{array}{l}\text { Prejuízo de mobiliários/ } \\
\text { equipamentos } 67 \%\end{array}$ \\
\hline Outeiro & $\begin{array}{l}\text { Assalto } 100 \% \\
\text { Inundação 0\% }\end{array}$ & Não 50\% & Mensalmente $60 \%$ & Sim $100 \%$ & $\begin{array}{l}\text { Prejuízo de mobiliários/ } \\
\text { equipamentos } 60 \%\end{array}$ \\
\hline Sacramenta & $\begin{array}{l}\text { Assalto 79\% } \\
\text { Inundação 4\% }\end{array}$ & $\operatorname{Sim} 62 \%$ & $\begin{array}{l}\text { Semanalmente } \\
41 \%\end{array}$ & $\operatorname{Sim} 100 \%$ & $\begin{array}{l}\text { Prejuízo de mobiliários/ } \\
\text { equipamentos } 35 \%\end{array}$ \\
\hline
\end{tabular}

Em relação à sensação, o risco é melhor traduzido pela palavra assalto, sendo escolhida pela maioria dos entrevistados em todos os distritos (mais de $73 \%$ em cada distrito). Esse dado revela que a população não percebe a inundação como o risco principal e, em alguns distritos, nem é percebida como risco, mas, ao invés disso, o risco de ser assaltado é o que mais preocupa.

Sobre a memória, os entrevistados foram perguntados se lembram das ocorrências de inundação no distrito de residência, Mosqueiro e Outeiro apresentaram maiores percentuais para a resposta $N a \tilde{o}$, todos os outros distritos apresentam maiores percentuais para a resposta Sim, além disso, aqueles entrevistados que responderam Não ou Não sei não responderam às perguntas seguintes, assim, entende-se que em todo o município uma parcela da população já presenciou algum episódio de inundação.

Sobre a frequência dos episódios de inundação no distrito de residência, a opção Mensalmente é a mais escolhida entre Benguí, Entroncamento, Icoaraci, Mosqueiro e Outeiro. Belém apresentou o maior percentual para a resposta Anualmente, o que pode ser considerada a menor frequência do município. Guamá e Sacramenta apresentaram a pior classificação dos entrevistados que assinalaram a resposta Semanalmente.

O distrito de Belém apresentou maior percentual de entrevistados com prejuízos de automóveis ou motocicletas. No Benguí e Icoaraci os entrevistados sofreram com interdição de via pública de acesso as suas residências, semelhantemente ao Entroncamento, onde os entrevistados sofreram com transtorno no trânsito. Mosqueiro, Outeiro, Guamá e Sacramenta, os entrevistados sofreram prejuízo de mobiliários e equipamentos. Dessa maneira, percebe-se que os danos e perdas estão relacionados com os meios de transporte e mobilidade urbana ou mobiliários e equipamentos.

Portanto, ao concluir o desenvolvimento das análises através da combinação da percepção técnica e a social, identifica-se quatro áreas de risco de acordo com as semelhanças e diferenças que as caracterizam. Decerto, essas percepções convergem numa mesma direção, sendo possível estruturar de forma lógica uma tabela com os resultados obtidos e consolidar a possibilidade de sua integração, conforme Tabela 2: 
Tabela 2: Percepção técnica e social do risco de inundação

\begin{tabular}{|c|c|c|c|c|c|c|}
\hline \multicolumn{2}{|l|}{ Áreas: } & Belém & $\begin{array}{l}\text { Entroncamento, } \\
\text { Benguí e } \\
\text { Icoaraci }\end{array}$ & $\begin{array}{l}\text { Outeiro e } \\
\text { Mosqueiro }\end{array}$ & $\begin{array}{l}\text { Guamá e } \\
\text { Sacramenta }\end{array}$ & \multirow{6}{*}{ 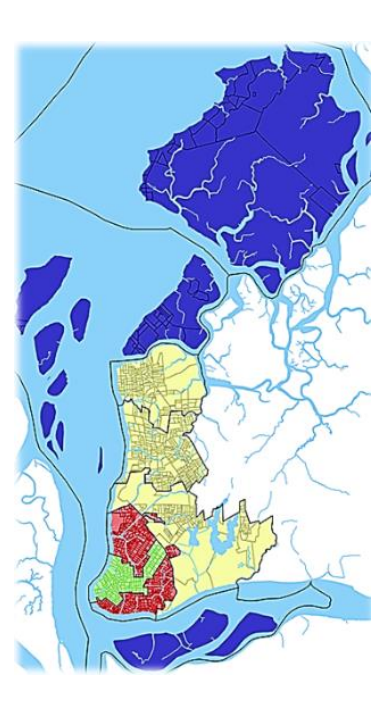 } \\
\hline \multirow{3}{*}{$\begin{array}{l}\text { Percepção } \\
\text { técnica }\end{array}$} & $\begin{array}{l}\text { Índice de risco } \\
\text { de inundação }\end{array}$ & Baixo & Baixo & Médio & Médio & \\
\hline & $\begin{array}{l}\text { Índice de } \\
\text { exposição }\end{array}$ & Alto & Alto & Muito alto & Muito alto & \\
\hline & $\begin{array}{l}\text { Índice de } \\
\text { vulnerabilidade }\end{array}$ & Médio & Médio & Médio & Médio & \\
\hline \multirow[b]{2}{*}{$\begin{array}{l}\text { Percepção } \\
\text { social }\end{array}$} & $\begin{array}{l}\text { Frequência das } \\
\text { inundações }\end{array}$ & Anualmente & Mensalmente & Mensalmente & Semanalmente & \\
\hline & $\begin{array}{l}\text { Perdas ou } \\
\text { danos } \\
\text { experimentados }\end{array}$ & $\begin{array}{l}\text { Prejuízo de } \\
\text { automóveis/ } \\
\text { motocicletas }\end{array}$ & $\begin{array}{l}\text { Outro: } \\
\text { transtorno no } \\
\text { trânsito; Outro: } \\
\text { interdição de } \\
\text { via pública de } \\
\text { acesso a minha } \\
\text { residência }\end{array}$ & $\begin{array}{l}\text { Prejuízo de } \\
\text { mobiliários/ } \\
\text { equipamentos }\end{array}$ & $\begin{array}{l}\text { Prejuízo de } \\
\text { mobiliários/ } \\
\text { equipamentos }\end{array}$ & \\
\hline
\end{tabular}

Percebe-se a heterogeneidade espacial do risco com ligação direta ao processo histórico de urbanização devido às dinâmicas de desenvolvimento da cidade. A formação da área central (área verde) se configurou por ser terras altas e saneadas, ocupadas por famílias de maior renda, enquanto que em sua envoltória, os terrenos baixos e inundáveis (área vermelha) se tornaram alternativas para famílias mais pobres (RODRIGUES et al, 2013).

$\mathrm{Na}$ área de expansão (área amarela), a ocupação ocorreu espontaneamente, na maioria dos casos com precariedade de infraestrutura urbana, sendo grandes lotes com configurações físicas de áreas inundáveis (RODRIGUES et al, 2013). Os distritos do Outeiro e Mosqueiro (área azul), também integrantes da área de expansão, mas formados por conjuntos de ilhas, concentram as menores densidades demográficas e infraestrutura urbana (PEREIRA, 2009).

\section{Conclusão}

Primeiramente, o índice do risco de inundação se constituiu como um instrumento útil para produção de informação, tendo como resultado a elaboração de mapas temáticos do risco e vulnerabilidade com a utilização de um SIG.

Vale salientar que há uma generalização substancial dos indicadores de vulnerabilidade, tendo em vista que estão disponíveis, em grande maioria, em tabelas numéricas incompatíveis com o formato SIG ou simplesmente em percentuais, portanto, é interessante que esses dados sejam disponibilizados em arquivos georreferenciados.

Outra questão é a falta um componente probabilístico, haja vista terem sido utilizadas informações demográficas do Censo 2010 e, também, na diferença de anos entre os bancos de dados dos indicadores.

Em seguida, a percepção social do risco de inundação se desenvolveu por meio de um processo participativo da população, tendo resultado na coleta de informações que contribuíram para a caracterização do risco. De fato, a aplicação do questionário tornou-se um desafio de comunicação e consulta aos cidadãos, sendo superado com sucesso para além das expectativas, haja vista a produção de informações próximas a realidade do município de Belém.

Em relação as suas limitações, o questionário apresentou uma relativa diversidade do público entrevistado, uma vez que não se obteve o mesmo percentual de respostas para cada distrito, o que permitiria a análise da percepção social mais fidedigna para cada área.

Portanto, pode-se concluir que o levantamento quantitativo dos indicadores de exposição e vulnerabilidade, assim como o da participação popular, permitiram uma avaliação qualitativa comparativa entre cada distrito que compõem a área de estudo. $O$ índice do risco de inundação constitui-se como uma ferramenta de análise espacial essencial ao suporte da tomada de decisão, especialmente por conseguir considerar indicadores de naturezas distintas para uma análise global das situações reais que o município tem enfrentado e, da mesma forma, o questionário firmou-se como uma ferramenta de análise social. 
Recomenda-se também para uma pesquisa futura, trabalhar em conjunto com peritos da engenharia ambiental, sanitária, de recursos hídricos, entre outros, com o objetivo de enriquecer este estudo por um olhar holístico ao agregar uma maior quantidade de informações de diversos pontos de vista. Um estudo dessa natureza traria uma compreensão maior da extensão do risco de inundação, ao adotar uma abordagem multifacetária, a fim de se produzir um documento rico em detalhes para a equalização das inundações.

Por último, recomenda-se a realização de um estudo comparativo entre cidades que apresentam ocorrências de inundação e tenham implementados projetos que obtiveram êxito na resolução desses problemas.

\section{Referências}

ALMEIDA, L. Q. Riscos ambientais e vulnerabilidade nas cidades brasileiras: conceitos, metodologias e aplicações. São Paulo: Cultura Acadêmica, 2012.

ALMEIDA, L. Q. et al. Disaster risk in indicators in Brazil: A proposal based on the world risk index. International Journal of Disaster Risk Reduction. Amsterdam: Elsevier, v. 17, p. 251-272, 2016.

AYRES, M. et al. 0 tamanho das amostras. Belém: Ponto Press, 2015.

BARBOSA, T. S. FURRIER, M. A geomorfologia antropogênica e a relação uso da terra com o risco geológico no município de João Pessoa - PB. São Paulo: Revista Brasileira de Geomorfologia, v. 18, n. 1, p. 169-184, jan.-mar./ 2017.

BELÉM. Anuário Estatístico do Município de Belém, v. 16, 2011. Belém: Secretaria Municipal de Coordenação Geral do Planejamento e Gestão, 2012.

BELÉM. Prefeitura no Bairro. Prefeitura de Belém, 02 abr. 2018. Disponível em: https://www.facebook.com/PrefeituraBelem/photos/a.568469636505906.134272.560599677292902/1 867288703290653/?type $=3 \&$ theater. Acesso em: 06 abr. 2018.

CAMPOS, T. L. O. B. et al. Eventos extremos de precipitação em Belém-PA: uma revisão de notícias históricas de jornais. Revista Ambiente \& Água: Taubaté, v. 10, n. 1, p. 182-194, jan.-mar./2014.

CERRI, L. E. S. AMARAL, C. P. Riscos Geológicos. In Oliveira, A. M. S. Brito, S. N. A. (eds). Geologia da Engenharia. São Paulo: Associação Brasileira de Geologia de Engenharia, 1998, p. 11-30.

CPRM. Cartas de suscetibilidade a movimentos gravitacionais de massa e inundações. Companhia de Pesquisa de Recursos Minerais. Serviço Geológico do Brasil, 22 abr. 2015. Disponível em: http://www.cprm.gov.br/publique/Gestao-Territorial/Geologia-de-Engenharia-e-RiscosGeologicos/Cartas-de-Suscetibilidade-a-Movimentos-Gravitacionais-de-Massa-e-Inundacoes3507.html\#para. Acesso em: 15 jan. 2018.

CRED. Annual Disaster Statistical Review 2016: the numbers and trends. Guha-Sapir, D. Hoyois, P. Wallemacq, P. Below, R. (ed.). Brussels: Université Catholique de Louvain. Centre for Research on the Epidemiology of Disasters, 2016.

ESTEVES, C. J. O. Risco e vulnerabilidade socioambiental: aspectos conceituais. Caderno IPARDES, Curitiba, v. 1, n. 2, p. 62-79, jul.-dez./2011.

GEOFABRIK. Download OpenStreetMap data fot this region: South America. Disponível em: https://download.geofabrik.de/south-america.html. Acesso em: 15 jan. 2018.

GUIVANT, J. S. A trajetória das análises de risco: da periferia ao centro da teoria social. Rio de Janeiro: Revista Brasileira de Informações Bibliográficas em Ciências Sociais, n. 46, p. 3-38, $2^{\circ}$ semestre de 1998. 
IBGE. Instituto Brasileiro de Geografia e Estatística. Disponível em: https://www.ibge.gov.br. Acesso em: 15 fev. 2018.

IPEA. Favelização no Brasil entre 2000 e 2010: resultados de uma classificação comparável. Mation, L. F. Nadalin, V. G. Krause, C. (ed.). Brasília: Instituto de Pesquisa Econômica Aplicada, 2014.

KELMAN, I. Lost for words amongst disaster risk science vocabulary? Beijing: Springer, International Journal of Disaster Risk Science, v. 9, n. 3, p. 281-291, set./2018.

MARCELINO, E. V. Desastres naturais e geotecnologias: conceitos básicos. Ministério da Ciência e Tecnologia. São José dos Campos: INPE, 2008. (INPE-15208-PUD/193).

MARCELINO, E. V. et al. Mapeamento de risco de desastres naturais do estado de Santa Catarina. Caminhos de Geografia, Uberlândia, n. 8, v. 17, p. 72-84, fev./2006

MENDES, J. M. et al. A vulnerabilidade social aos perigos naturais e tecnológicos em Portugal. Centro de Estudos Sociais da Universidade de Coimbra. Coimbra, Revista Crítica de Ciências Sociais, v. 93, p. 95-128, 2011.

OLÍMPIO, J. L. S. ZANELLA, M. E. Riscos naturais: conceitos, componentes e relações entre natureza e sociedade. Raega - O espaço geográfico em análise, Curitiba, v. 40, p. 94-109, ago./2017.

PEREIRA, I. S. O. As políticas públicas de revitalização urbana e a localização das classes sociais: o caso de Belém - PA. Brasília, 2009. 305 f. Tese (Doutorado em Urbanismo) - Faculdade de Arquitetura e Urbanismo, Universidade de Brasília, Brasília, 2005.

PINHEIRO, A. C. L. Aglomerados subnormais em Belém: risco e vulnerabilidade socioambiental. Belém, 2015. 134 f. Dissertação (Mestrado em Arquitetura e Urbanismo) - Faculdade de Arquitetura e Urbanismo, Universidade Federal do Pará, Belém, 2015.

PONTES, M. L. C. et al. Dinâmica das áreas de várzea do município de Belém/PA e a influência da precipitação pluviométrica na formação de pontos alagamentos. Pontifícia Universidade Católica de Minas Gerais. Belo Horizonte, Caderno de Geografia, v. 27, n. 49, abr.-jun./2017.

RODRIGUES, R. M. et al. Urbanizar as "baixadas": experiências de projetos de urbanização de assentamentos precários em áreas de preservação permanente em Belém (PA). In: ENCONTRO DA ASSOCIAÇÃO NACIONAL DE PESQUISA E PÓS-GRADUAÇÃO EM ARQUITETURA E URBANISMO, 4., Porto Alegre, 2016. Anais [...]. Porto Alegre: Universidade Federal do Rio Grande do Sul, 2016. p. 1-25.

SANTOS, V. J. et al. O Conceito de risco. Programa de Pós-Graduação em Geografia da Universidade Federal de Juiz de Fora. Juiz de Fora, Revista de Geografia, v. 5, n. 1, p. 33-42, jan.-jun./2015.

SOUZA, K. R. G. LOURENÇO, L. A evolução do conceito de risco à luz das ciências naturais e sociais. Associação Portuguresa de Riscos, Prevenção e Segurança. Coimbra, Territorium: Revista Portuguesa de Riscos, Prevenção e Segurança, v. 22, n. 1, p. 31-44, jan.-jul./2015.

TAVARES, E. G. et al. Da sociedade industrial à sociedade de risco: abordagens acerca da relação direta e proporcional entre atividade econômica e aumento do risco ecológico segundo as obras de Ulrich Beck. Blumenau, Revista Jurídica - CCJ, v. 21, n. 45, p. 63-88, maio-ago./2017.

UNISDR. Making Cities Resilient: My City is Getting Ready! - campaign kit. United Nations International Strategy for Disaster Reduction, 2010. Disponível em: https://www.unisdr.org/we/inform/publications/14043. Acesso em: 04 out. 2017.

UNISDR. Como Construir Cidades Mais Resilientes: Um Guia para Gestores Públicos Locais. Genebra: United Nations International Strategy for Disaster Reduction, 2012. Disponível em: http://eird.org/camp-10-15/port/ferramentas.html. Acesso em: 15 out. 2017. 
VEYRET, Y. Introdução. In: VEYRET, Y. Os riscos: o homem como agressor e vítima do meio ambiente, São Paulo: Contexto, 2007. p. 11-21.

WRR. WorldRiskReport 2016. Alliance Development Works and United Nations University Environment and Human Security (UNU-EHS). University Stuttgart. Disponível em: http://weltrisikobericht.de/wp-content/uploads/2016/08/WorldRiskReport2016.pdf. Acesso em: 15 out. 2017.

Esta obra está licenciada com uma Licença Creative Commons Atribuição 4.0 Internacional. 